\title{
Degradation of diclofenac in aqueous solution by homogeneous and heterogeneous photolysis
}

\author{
Irina Epold' ${ }^{1}$ Niina Dulova', Marina Trapido ${ }^{1 *}$ \\ Correspondence: marina.trapido@ttu.ee \\ 'Department of Chemical Engineering, Tallinn University of Technology, Ehitajate tee 5, Tallinn, Estonia.
}

\begin{abstract}
Background: Pharmaceuticals have arisen as emerging environmental pollutants due to their potential impact on humans, animals and microorganisms even at low concentrations. Conventional wastewater treatment plants are known to be ineffective for removal of many pharmaceuticals present in wastewater. Advanced oxidation processes are one of the most promising treatment technologies for degradation of such persistent compounds. The current study was focused on the efficacies of various oxidation processes for degradation of diclofenac (DCF) as one of the most widespread pharmaceuticals.

Methods: The efficacy of UV photolysis, hydrogen peroxide photolysis, homogeneous and heterogeneous Fenton/photoFenton treatment for removal of DCF from aqueous solution was examined. The impact of $\mathrm{pH}$, hydrogen peroxide concentration, and catalyst type on DCF removal was assessed. The identification of DCF photo-degradation products with GC-MS (EI) technique was carried out.

Results: According to results of the present study direct photolysis proved main contributing reaction pathway in all studied systems with UV irradiation. Fast decrease in $\mathrm{pH}$ value observed during all studied processes started at $\mathrm{pH}$ 5, 7, and 9 led to the system controlled by DCF precipitation-degradation-re-dissolution conditions. The enhanced efficacy of promoted photolysis proved dependent on the rate of $\mathrm{pH}$ decrease to value below $\mathrm{pK}_{\mathrm{a}}$ at the beginning of the process. After reaching acidic $\mathrm{pH}$ values of the surrounding solution the DCF degradation was controlled by the solubility independently of treatment method applied. The highest DCF degradation efficacy was attained by the heterogeneous photo-Fenton treatment at initial $\mathrm{pH}$ 11. Thus, DCF 90\% conversion time decreased from 48 to $23.5 \mathrm{~min}$ for UV photolysis and heterogeneous photo-Fenton process $\left(3.8 \mathrm{mM} \mathrm{H}_{2} \mathrm{O}_{2}\right)$, respectively.

Conclusions: DCF was quite resistant to all tested processes. The application of the Fenton-based treatment and $\mathrm{UV} / \mathrm{H}_{2} \mathrm{O}_{2}$ did not show vital advantages compared to UV photolysis when the initial $\mathrm{pH}$ was 7 or 9. Direct photolysis proved main process contributing to DCF degradation in all studied systems combined with UV irradiation. The present study was the first to evaluate the efficacy of photo-Fenton catalysed by goethite for DCF degradation in aqueous solution. The latter proved the most efficient one among the Fenton-based processes.
\end{abstract}

Keywords: Advanced oxidation processes, photolysis, photo-Fenton process, pharmaceutical, UVC radiation, goethite

\section{Background}

The presence of pharmaceutical residues in municipal, surface, ground- and even drinking water is an emerging environmental problem due to the potential impact on human health and the environment even at low concentrations. Pharmaceuticals used by human or animal are only partially consumed in the organism and excreted through urine or faeces in unchanged or/and metabolized form. Drugs are released into the wastewater not only after medical application, but also during manufacturing and improper disposal of unused or expired medicines. Unit operations used in wastewater treatment plants (WWTP) are known to be ineffective for removal of many pharmaceuticals present in wastewater. Consequently, effluents finally released into the receiving water bodies contain from ng L-1 to $\mu \mathrm{g} \mathrm{L}^{-1}$ of these pollutants [1-2].

Among the various pharmaceuticals, non-steroidal anti-inflammatory drugs (NSAIDs) are of the greatest environmental interest due to their widespread availability. Diclofenac (2-(2,6-dichlorophenylamino) phenylacetic acid, DCF) is one of the most consumed NSAIDs (annual DCF consumption estimated as 940 tons [3]) commonly used in medical care as an analgesic, antiarthritic and antirheumatic agent. Being resistant to biodegradation, it is ubiquitously present in the aquatic environment and detected in effluents of WWTP [3]. This pharmaceutical is relatively stable in the environment, but similar to others NSAIDs is sensitive to photolysis. DCF is known to undergo solar radiation induced photochemical decomposition in surface waters. However, it is still one of the most frequently

(c) 2012 Trapido et al; licensee Herbert Publications Ltd. This is an open access article distributed under the terms of Creative Commons Attribution License (http://creativecommons.org/licenses/by/3.0),This permits unrestricted use, distribution, and reproduction in any medium, provided the original work is properly cited. 
detected compounds in water at concentrations up to $2 \mu \mathrm{g} \mathrm{L}^{-1}$ [4]. Although the ecotoxicity of DCF is relatively low, in combination with other drugs present in water, the toxic effects increase considerably [5]. Conventional WWTP, typically based on biological processes, are capable of removing some substances, but non-biodegradable compounds (e.g. DCF) may escape the treatment.

Advanced oxidation processes (AOPs) are one of the most promising treatment technologies for successful degradation of pharmaceuticals in aqueous matrices [6]. Several AOPs have been tested for DCF removal from water/ wastewater including photolysis and $\mathrm{UV} / \mathrm{H}_{2} \mathrm{O}_{2}$ process [6-7], homogeneous Fenton/photo-Fenton oxidation $[\mathbf{2}, \mathbf{5}]$, heterogeneous catalytic oxidation with $\mathrm{H}_{2} \mathrm{O}_{2}$ [9], etc. However, among the various advanced oxidation technologies proposed for the degradation of DCF the heterogeneous Fenton-based process with goethite catalyst has not yet been investigated.

The main drawbacks associated with homogeneous catalysts in the Fenton process are the narrow $\mathrm{pH}$ range of operation to avoid the formation and subsequent precipitation of iron oxyhydroxide and the need to recover dissolved iron ions from the treated solution by supplementary treatment process. The application of heterogeneous catalyst (e.g. naturally occurring minerals) in the Fenton treatment overcomes the above-mentioned problems and results in extended periods of catalyst life without requiring regeneration or replacement, in easy removal of the catalyst from the treated water by sedimentation or filtration, and in Fenton-like reactions over a wide range of $\mathrm{pH}$ value [10]. The heterogeneous Fentonbased processes involving naturally occurring minerals (hematite $\mathrm{a}-\mathrm{Fe}_{2} \mathrm{O}_{3^{\prime}}$ goethite a-FeOOH, magnetite $\mathrm{Fe}_{3} \mathrm{O}_{4^{\prime}}$ etc.) proved feasible alternative for water/wastewater treatment [11]. Goethite has been recognized as the preferred mineral oxide catalyst since it appears to have the fastest reaction with $\mathrm{H}_{2} \mathrm{O}_{2}$ [12].
In the present study the degradation of DCF using UV photolysis, $\mathrm{H}_{2} \mathrm{O}_{2}$ photolysis, homogeneous and heterogeneous Fenton/photo-Fenton processes was investigated. The efficacies of various oxidation processes on DCF removal from aqueous solution were compared. The identification of main by-products of DCF degradation by AOPs applied was carried out.

\section{Methods \\ Chemicals and materials}

Diclofenac sodium salt and goethite (a-FeOOH, 30-50 mesh) were purchased from Sigma-Aldrich; acetonitrile (99.8\%, isocratic grade for HPLC) was obtained from Baker. The structure and the basic data concerning DCF are presented in Table 1. The specific surface area of goethite was measured by multipoint $\mathrm{N}_{2}$-BET analysis using a sorptometer KELVIN 1042 (COSTECH Instruments) as $112.5 \mathrm{~m}^{2} \mathrm{~g}^{-1}$. All other chemicals were of analytical grade and used without further purification.

Stock solutions with initial DCF concentration of $100 \mathrm{mg}$ $\mathrm{L}^{-1}$ were prepared in twice-distilled water. The solution was mixed for several hours to achieve complete DCF dissolution. As the solubility of DCF is low below the $\mathrm{pK}_{\mathrm{a}}$ value (4.15), all experiments were conducted at initial $\mathrm{pH} \geq 5$. Sodium hydroxide and sulphuric acid aqueous solutions were used for $\mathrm{pH}$ adjustment.

\section{Experimental procedure}

A mercury low-pressure OSRAM lamp with an energy input of $10 \mathrm{~W}$ located in a quartz tube inside the reactor was used as an UV source. The incident UV radiation photon flux at $254 \mathrm{~nm}$ measured by potassium ferrioxalate actinometry [13] was 3.59 $\pm 0.12 \mu$ Einstein $\mathrm{s}^{-1}$. The constant temperature $\left(22 \pm 1^{\circ} \mathrm{C}\right)$ in the reactor was maintained using a cooling jacket. All Fenton-based process trials were carried out in batch mode and in non-buffered solutions. DCF solutions were treated in $1 \mathrm{~L}$ cylindrical glass reactor with permanent

Table 1. The structure and main properties of studied pharmaceutical

\begin{tabular}{ll}
\hline Pharmaceutical & Diclofenac sodium salt \\
Empirical formula & $\mathrm{C}_{14} \mathrm{H}_{10} \mathrm{Cl}_{2} \mathrm{NNaO}_{2}$ \\
Molecular formula & $15307-79-6$ \\
$\mathrm{CAS}$ Nr. & 318.13 \\
Molecular weight, $\mathrm{g} \mathrm{mol}^{-1}$ & $4.15[3]$ \\
pK
\end{tabular}


agitation at a speed to provide complete mixing for uniform distribution and full suspension of iron catalyst particles for a period of $120 \mathrm{~min}$; samples were withdrawn at selected time intervals and filtered through a Millipore filter ( 0.45 $\mu \mathrm{m})$. The reaction was stopped by adding 2 drops of $1 \mathrm{M}$ aqueous solution of $\mathrm{NaOH}$.

The homogeneous Fenton reaction $\left(\mathrm{H}_{2} \mathrm{O}_{2} / \mathrm{Fe}^{2+}\right)$ was initiated by adding $\mathrm{H}_{2} \mathrm{O}_{2}(0.94-2.5 \mathrm{mM}$ ) to DCF solution ( $\mathrm{pH} 5$ or pH 7) containing a known amount of $\mathrm{Fe}^{2+}$ ion. The molar ratio of $\mathrm{H}_{2} \mathrm{O}_{2} / \mathrm{Fe}^{2+}$ was kept invariable at 10:1. Heterogeneous Fenton-based treatment trials $\left(\mathrm{H}_{2} \mathrm{O}_{2} / \mathrm{a}-\mathrm{FeOOH}\right)$ were carried out with $1 \mathrm{~g} \mathrm{~L}^{-1}$ of goethite at $\mathrm{pH}$ values of 7 . The suspensions were continuously stirred for 30 min prior to $\mathrm{H}_{2} \mathrm{O}_{2}$ addition to establish the adsorption/desorption equilibrium between the DCF and the catalyst particles.

The photo-Fenton experiments were carried out in the same reactor and treatment conditions as the Fenton experiments with the UV lamp located inside the reactor. In the homogeneous photo-Fenton trials the concentration of hydrogen peroxide was in the range of 0.63-1.9 mM; the $\mathrm{pH}$ value of the stock solution was adjusted to 7 . The heterogeneous photo-Fenton experiments were carried at $\mathrm{pH}$ values of 7,9 and 11 with $\mathrm{H}_{2} \mathrm{O}_{2}$ concentration from 0.63 to $3.8 \mathrm{mM}$.

The direct UV photolysis and $\mathrm{H}_{2} \mathrm{O}_{2} / \mathrm{UV}$ experiments were carried out in the same reactor $(1 \mathrm{~L}$ of stock DCF solution in a glass reactor with a permanent agitation speed for a period of $120 \mathrm{~min}$ ). The $\mathrm{pH}$ value of the stock solution was in the range of 5 to 11 . The $\mathrm{H}_{2} \mathrm{O}_{2}$ concentration varied from 0.63 to $1.9 \mathrm{mM}$.

Additionally, the experiments on adsorption effect of goethite and DCF oxidation with non-catalyzed hydrogen peroxide were conducted in the same reactor and treatment conditions as the respective Fenton-based treatment trials. All experiments were duplicated and the data on DCF concentration was verified with at least three replicates. The results of the analysis of initial and treated samples are presented as the mean, with the standard deviation below $4 \%$ in all cases.

\section{Analytical methods}

DCF concentrations were quantified by means of a CLAS MPm (Labio Ltd.) high performance liquid chromatograph equipped with a MAG $0(1.5 \times 50 \mathrm{~mm})$ Biospher PSI 100 C18 (particle size, $5 \mu \mathrm{m}$ ) microcolumn and UV/VIS detector SAPHIRE. The isocratic method with a solvent mixture of $50 \%$ acetonitrile and $0.1 \%$ of acetic acid in water was applied. Samples were analyzed at a flow rate of $70 \mu \mathrm{L} \mathrm{min}-1$ and absorbance wavelength of $254 \mathrm{~nm}$. The concentration of DCF was determined by using the standard chemical to fit the retention time.

The total iron concentration was quantified with phenanthroline method [14]. The initial hydrogen peroxide concentration in stock solutions was determined spectrophotometrically by measurement of the absorption of hydrogen peroxide at $\lambda=254 \mathrm{~nm}$. The residual hydrogen peroxide concentration was measured by the spectrophotometric method with $\mathrm{Ti}^{4+}$ [15]. The chemical oxygen demand (COD) was determined by the closed reflux titrimetric method according to [14]. The correction of hydrogen peroxide interference on COD test was done by the correlation equation according to [16].

\section{Identification of DCF degradation by-products}

The samples from selected trials were concentrated to dryness by water evaporation at room temperature and re-dissolved in methanol to a final volume of $2 \mathrm{~mL}$.

GC-MS measurements were performed with a gas chromatograph GC-2010 (Shimadzu, Kyoto, Japan) equipped with a GCMS-QP2010 Plus mass selective detector. The column flow was maintained at $1.66 \mathrm{~mL} \mathrm{~min}^{-1}$. The analytes were separated in a ZB-5MS column $(30 \mathrm{~m} \times 0.32 \mathrm{~mm} \times 0.25$ $\mu \mathrm{m})$. The oven temperature program was $1.0 \mathrm{~min}$ at $105^{\circ} \mathrm{C}$, $25^{\circ} \mathrm{C} \mathrm{min}-1$ to $180^{\circ} \mathrm{C}, 5^{\circ} \mathrm{C} \mathrm{min}-1$ to $250^{\circ} \mathrm{C}, 20^{\circ} \mathrm{C} \mathrm{min}-1$ to 270 (holding time $3 \mathrm{~min}$ ). The interface temperature was set at $280^{\circ} \mathrm{C}$. The injector and the ion source temperature were 270 and $250^{\circ} \mathrm{C}$, respectively. The MS detector was operated in the El mode, scanning in the range of $50-400 \mathrm{~m} / \mathrm{z}$.

\section{Results and Discussion}

\section{$\mathrm{UV}$ photolysis and $\mathrm{UV} / \mathrm{H}_{2} \mathrm{O}_{2}$ process}

DCF effectively absorbs UV light in the range between 200 and $300 \mathrm{~nm}$ with the absorption maximum at $273 \mathrm{~nm}$, which tails well over $300 \mathrm{~nm}$ when the spectrum is measured up to $400 \mathrm{~nm}$. In general, DCF is known to undergo both long wave and short wave UV photolysis. The former may occur even in natural surface water systems.

The experiments of UV photolysis and $\mathrm{UV} / \mathrm{H}_{2} \mathrm{O}_{2}$ treatment of DCF were performed as preliminary trials for subsequent assessment of homogeneous and heterogeneous photoFenton treatment efficacy. In direct photolysis trials a spontaneous $\mathrm{pH}$ drop to 3.5 due to formation of hydrochloric and carboxylic acids was observed leading to precipitation of DCF (Figure 1). DCF is very water soluble in neutral-alkaline medium $\left(50 \mathrm{~g} \mathrm{~L}^{-1}\right)$, but has low solubility $\left(23.7 \mathrm{mg} \mathrm{L}^{-1}\right)$ at $\mathrm{pH}$ below $\mathrm{pK}_{\mathrm{a}}$ value [17]. Thus, under such acidic conditions, DCF precipitates from the solution.

In UV photolysis at $\mathrm{pH}$ 5, DCF was completely precipitated at the beginning and the process kinetics was entirely governed by the continuous re-dissolution of DCF. $90 \%$ conversion was not achieved during $2 \mathrm{~h}$ of oxidation and the highest DCF removal was $85 \%$. Therefore, DCF degradation was still occurring at $\mathrm{pH}$ around 3.5, even though it had undergone slight precipitation during the treatment, due to simultaneous precipitation-degradation-re-dissolution process. Similar observation was reported by [5]. In the case of direct photolysis experiment started at $\mathrm{pH} 7$ and 9 , fast decrease in $\mathrm{pH}$ also led to the system controlled by DCF re-dissolution process (Figure 1). However, in both cases $90 \%$ conversion was achieved in 115 and 80 min for 


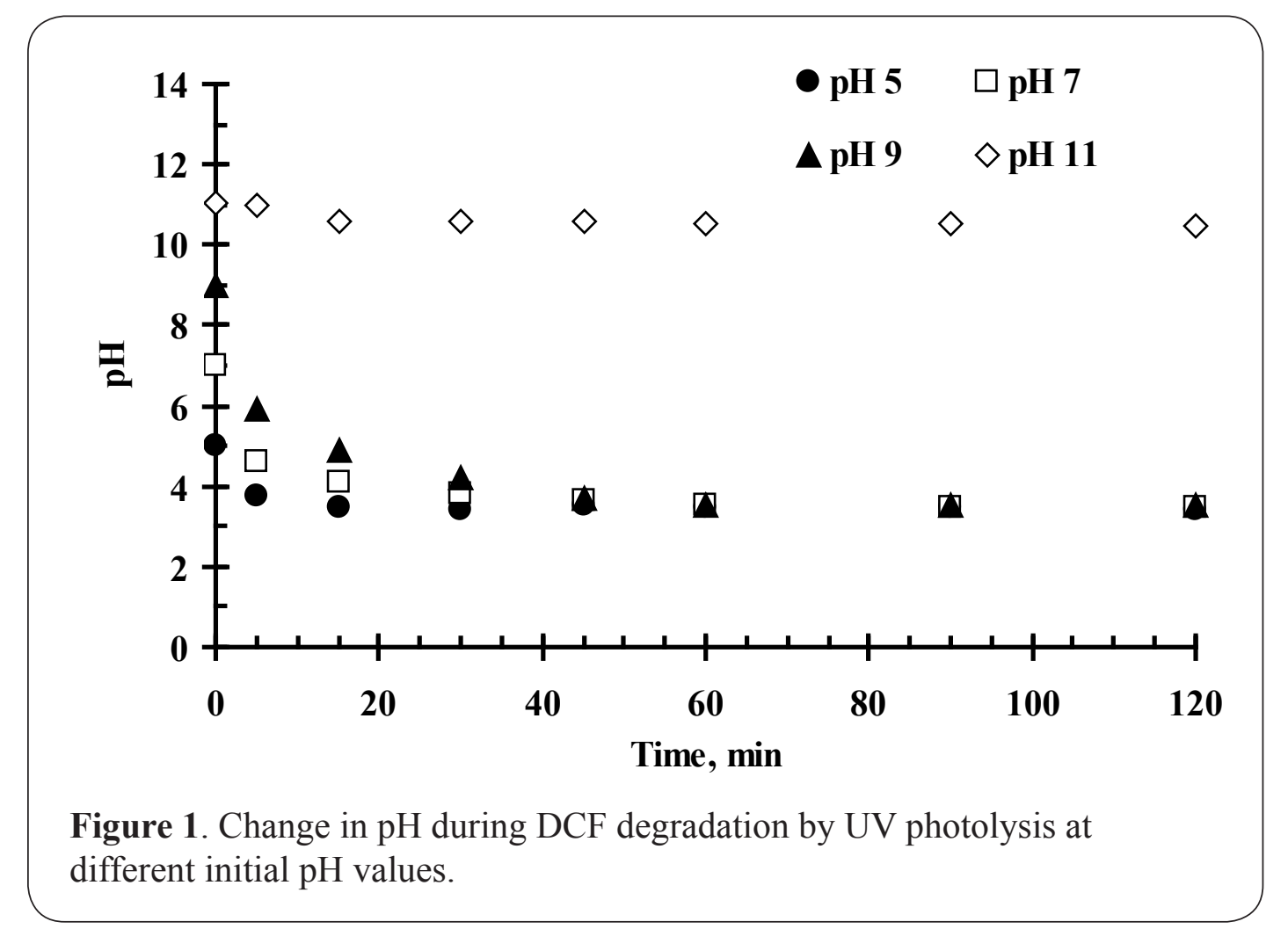

$\mathrm{pH} 7$ and 9, respectively (Figure 2). Faster DCF removal compared to the trial at $\mathrm{pH} 5$ was mainly due to effective drug degradation at the beginning of the treatment, i.e. pending $\mathrm{pH}$ decrease from initial to below $\mathrm{pK}_{\mathrm{a}}$ value.

Rivas et al., [18] suggested that addition of free radical promoters does not enhance the efficiency of UV photolysis when irradiated substances have relatively high values of quantum yield $(\varphi)$ and molar absorption coefficient $(\varepsilon)$; moreover, a negative effect can be experienced. Reported $\varepsilon$ and $\varphi$ for DCF UV photolysis at $254 \mathrm{~nm}$ are $4260 \pm 130 \mathrm{M}^{-1}$ $\mathrm{cm}^{-1}$ and $0.272 \pm 0.046 \mathrm{~mol}^{2}$ Einstein ${ }^{-1}$, respectively [19]. On the other hand, Vogna et al., [20] found that addition of hydrogen peroxide to UV system effectively induced DCF degradation. In the present study, different concentrations of hydrogen peroxide were tested to increase UV photolysis efficacy.

Similar to UV photolysis the efficacy of $\mathrm{UV} / \mathrm{H}_{2} \mathrm{O}_{2}$ process proved dependent on the solubility equilibrium of DCF controlled by the $\mathrm{pH}$ of the surrounding solution. The results indicated that DCF transformation in the UV/ $\mathrm{H}_{2} \mathrm{O}_{2}$ process was influenced by direct photolysis; i.e. UV photolysis was responsible for $85-100 \%$ of DCF degradation by UV/ $\mathrm{H}_{2} \mathrm{O}_{2}$ system (Figure 2). The addition of 0.63 and $0.94 \mathrm{mM} \mathrm{H}_{2} \mathrm{O}_{2}$ resulted in negligible efficacy enhancement or even in worse DCF reduction compared to UV photolysis independently of the initial $\mathrm{pH}$ value. Further increase in $\mathrm{H}_{2} \mathrm{O}_{2}$ concentration to $1.9 \mathrm{mM}$ led to improvement in DCF degradation with
pH increase from 7 to 11 (Figure 2). Thus, 90\% conversion time $\left(T_{90 \%}\right)$ decreased from 48 to $28.5 \mathrm{~min}$ for UV photolysis and $\mathrm{UV} / \mathrm{H}_{2} \mathrm{O}_{2}$ process at $\mathrm{pH} 11$, respectively.

Blank trials with non-catalyzed hydrogen peroxide were performed at the same initial concentrations as the photo-catalytic experiments. No degradation of DCF was detected during $2 \mathrm{~h}$ of $\mathrm{H}_{2} \mathrm{O}_{2}$ oxidation.

Overall UV and hydrogen peroxide photolysis treatment efficacy was assessed by measuring COD. Low mineralization (not exceeding $15 \%$ after $2 \mathrm{~h}$ of oxidation) was observed in any case according to measured COD values. This fact indicated the formation of intermediates, which are more resistant to the photo-degradation than DCF itself.

\section{The Fenton and photo-Fenton treatment}

The Fenton process trials $\left(\mathrm{H}_{2} \mathrm{O}_{2} / \mathrm{Fe}^{2+}\right)$ were conducted at $\mathrm{pH} 5$ and 7. The experiments with initial $\mathrm{pH} 5$ indicated rapid $\mathrm{pH}$ decrease below $\mathrm{pK}_{\mathrm{a}}$ value, resulting in the system completely controlled by precipitation-degradation-re-dissolution process. DCF removal during $2 \mathrm{~h}$ was very moderate, e.g. $25 \%$ in trial with $0.94 \mathrm{mM} \mathrm{H}_{2} \mathrm{O}_{2}$. The increase in initial pH to 7 resulted in improved DCF removal (40 and $70 \%$ of DCF were degraded during the Fenton treatment at 0.94 and $2.5 \mathrm{mM} \mathrm{H}_{2} \mathrm{O}_{2}$ concentration, respectively). However, fast $\mathrm{pH}$ decrease was still observed in systems with $\mathrm{pH} 7$ indicating effective degradation of DCF at the beginning of the Fenton reaction and subsequent slow removal 


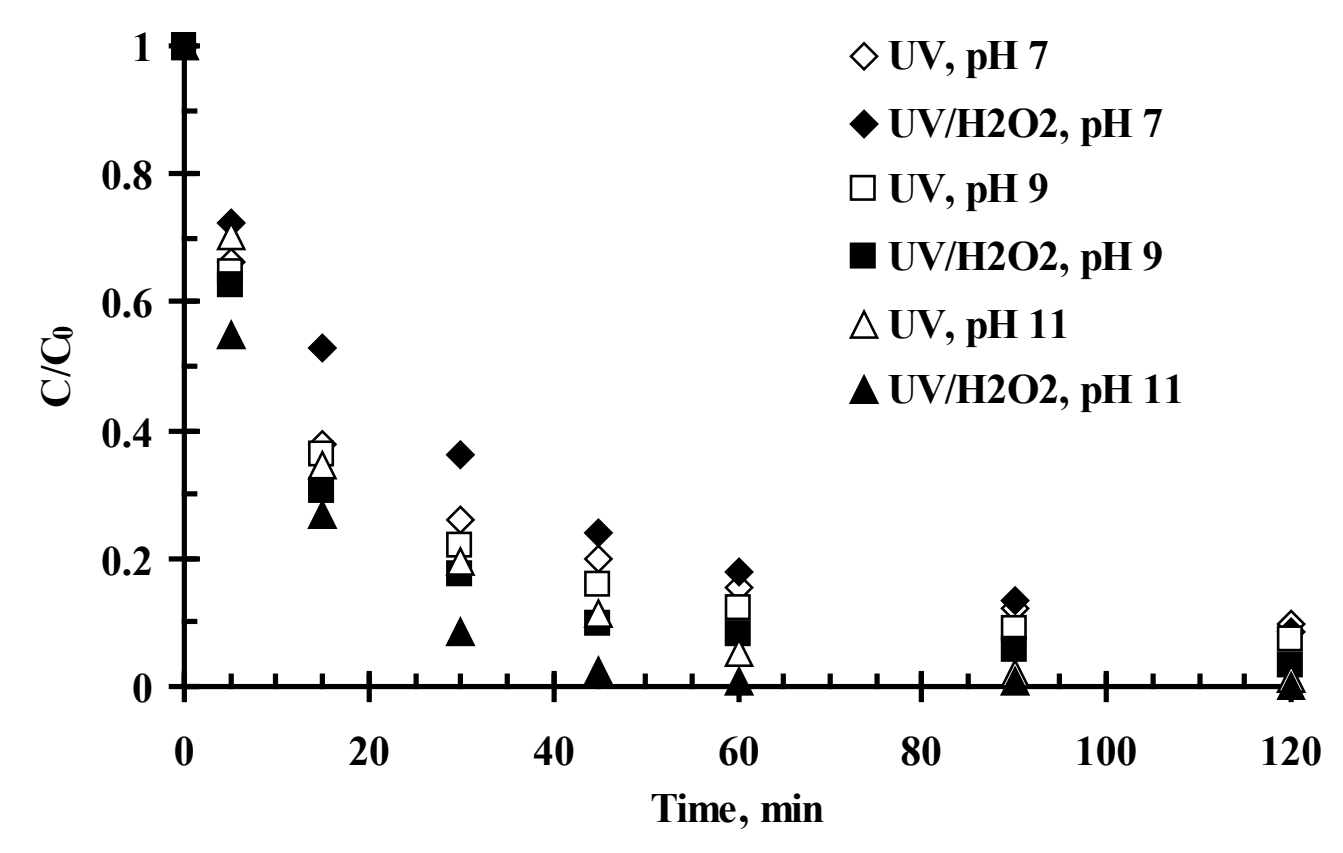

Figure 2. DCF degradation by $\mathrm{UV}$ photolysis and $\mathrm{UV} / \mathrm{H}_{2} \mathrm{O}_{2}$ process $\left(1.9 \mathrm{mM} \mathrm{H}_{2} \mathrm{O}_{2}\right)$ at different $\mathrm{pH}$ values.

influenced by drug's re-dissolution.

As to the heterogeneous Fenton process, the goethite catalysed Fenton-based reaction is a surface controlled process that depends on $\mathrm{H}_{2} \mathrm{O}_{2}$ concentration, on the iron mineral surface area and on other system parameters $(\mathrm{pH}$, etc.). The overall heterogeneous reaction will include various steps such as diffusion of chemicals to the surface, surface complex formation, actual electron transfer, desorption of products, and regeneration of the reactive sites [10].

The results showed no removal of DCF during 2 hours of the heterogeneous Fenton reaction independent of $\mathrm{H}_{2} \mathrm{O}_{2}$ concentration in the range of 0.63-3.8 $\mathrm{mM}$. The amount of the total dissolved iron in the bulk solution for $\mathrm{H}_{2} \mathrm{O}_{2} / \mathrm{a}$ $\mathrm{FeOOH}$ system was less than $0.03 \mathrm{mg} \mathrm{L}^{-1}$ after 120 min of oxidation, indicating solely heterogeneous pathway of reaction. Some decrease in $\mathrm{H}_{2} \mathrm{O}_{2}$ concentration observed during the goethite catalyzed Fenton-based oxidation is most likely due to partial $\mathrm{H}_{2} \mathrm{O}_{2}$ decomposes to oxygen and water at the surface of the heterogeneous catalysts without producing dissolved radicals [10]. Prolonged experiments with overall duration of $24 \mathrm{~h}$ resulted in negligible degradation of DCF with less than $5 \%$ removal. The sorption experiments demonstrated no DCF removal due to adsorption on the catalyst surface.

Since solely $\mathrm{H}_{2} \mathrm{O}_{2}$ did not led to complete mineralization of DCF by UV/ $\mathrm{H}_{2} \mathrm{O}_{2}$ process the photo-Fenton treatment proved promising alternative to enhance DCF degradation in aqueous solution. Similar to direct and hydrogen peroxide photolysis the photo-Fenton process (both homogeneous and heterogeneous) kinetics were governed by the continuous re-dissolution of DCF. Thus, trials with initial $\mathrm{pH} 7$ and 9, demonstrated $\mathrm{pH}$ decrease to 3.5 during the experiment.

The homogeneous photo-Fenton treatment was conducted at initial $\mathrm{pH}$ 7. Iron precipitated at this $\mathrm{pH}$ value producing highly light-absorbing iron hydroxide colloids. In general, photo-reductive decomposition of ferric-complexes can release ferrous iron to the solution, which will produce additional hydroxyl radicals in the presence of hydrogen peroxide. The results of DCF removal revealed similarity among the homogeneous photo-Fenton process and UV/ $\mathrm{H}_{2} \mathrm{O}_{2}$ system ( $\mathrm{pH}$ 7). Thus, DCF degradation was slower during $\mathrm{UV} / \mathrm{H}_{2} \mathrm{O}_{2} / \mathrm{Fe}^{2+}$ process compared to direct photolysis at neutral $\mathrm{pH}$ value. This fact can be explained by faster decrease in $\mathrm{pH}$ below $\mathrm{pK}_{\mathrm{a}}$ value leading to the treatment process controlled by continuous DCF re-dissolution.

The heterogeneous photo-Fenton trials were conducted at $\mathrm{pH}$ in the range from 7 to 11 . Generally, minerals containing ferric oxides (e.g. goethite) need ultraviolet radiation to accelerate the reduction of $\mathrm{Fe}^{3+}$ to $\mathrm{Fe}^{2+}$. The results of goethite catalysed photo-Fenton system indicated similarity to $\mathrm{UV} / \mathrm{H}_{2} \mathrm{O}_{2}$ process as the increase in $\mathrm{H}_{2} \mathrm{O}_{2}$ concentration and $\mathrm{pH}$ led to additional DCF removal if compared to direct photolysis (Figures 3 \& 4). Thus, $\mathrm{T}_{90 \%}$ was decreased from 115 


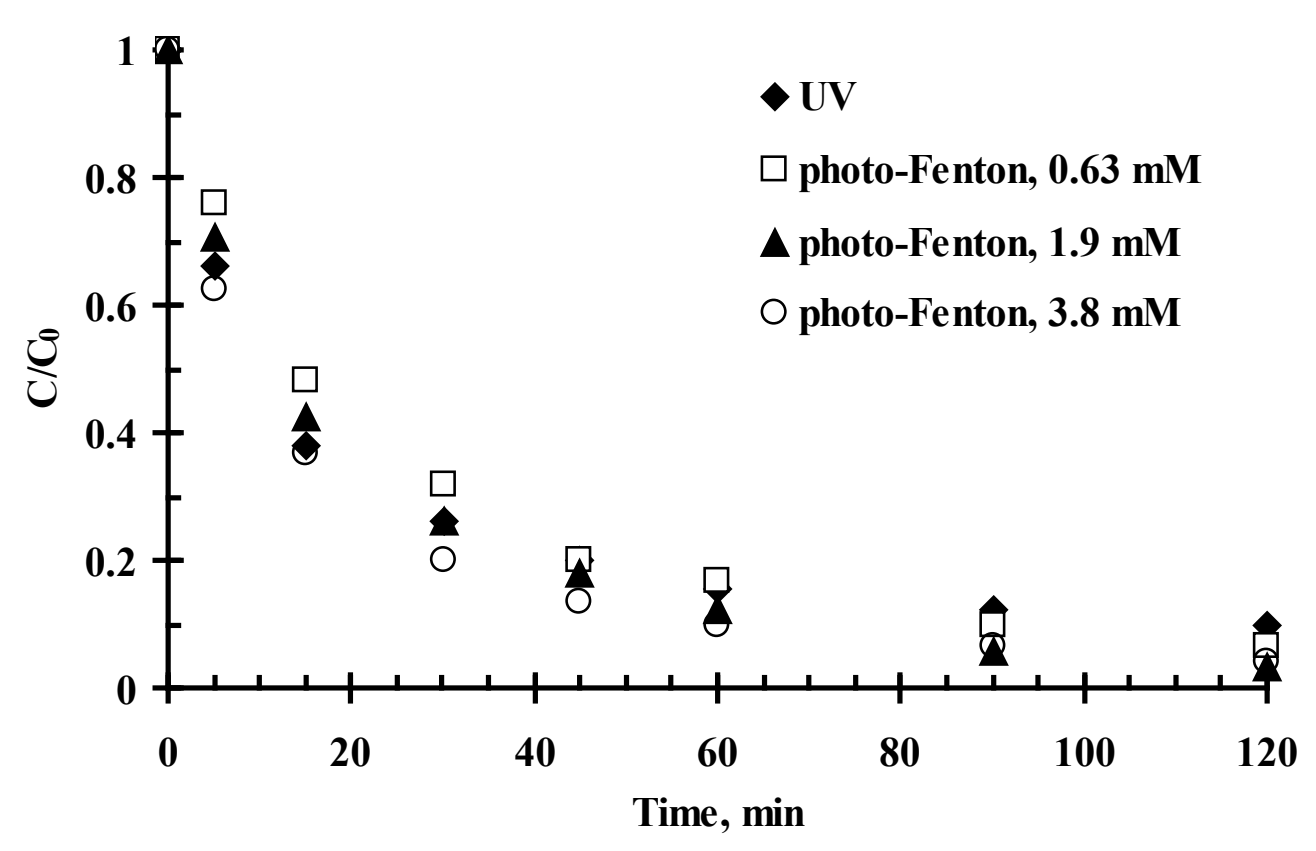

Figure 3. DCF degradation by heterogeneous photo-Fenton treatment $(\mathrm{pH} 7)$ at different $\mathrm{H}_{2} \mathrm{O}_{2}$ concentrations.

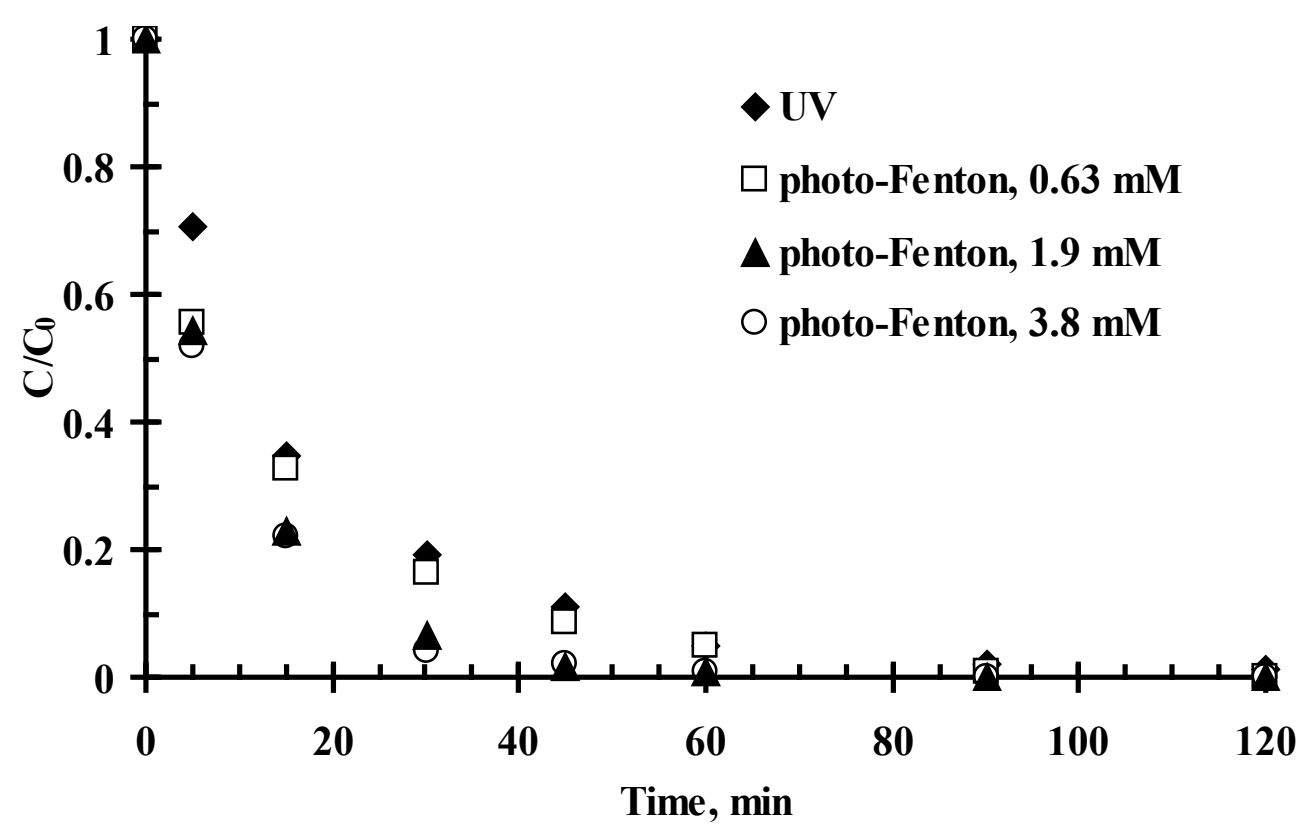

Figure 4. DCF degradation by heterogeneous photo-Fenton treatment $(\mathrm{pH} 11)$ at different $\mathrm{H}_{2} \mathrm{O}_{2}$ concentrations. 
to $69 \mathrm{~min}$ and from 80 to $42 \mathrm{~min}$ for photo-Fenton treatment (1.9 $\mathrm{mM} \mathrm{H}_{2} \mathrm{O}_{2}$ ) at pH 7 and 9, respectively, if compared to direct photolysis. The $\mathrm{H}_{2} \mathrm{O}_{2}$ utilization in the heterogeneous photo-Fenton and $\mathrm{UV} / \mathrm{H}_{2} \mathrm{O}_{2}$ processes was comparable as well and resulted in $25-30 \%$ at $\mathrm{pH} 7$ and 9 . At $\mathrm{pH} 11$ residual $\mathrm{H}_{2} \mathrm{O}_{2}$ concentrations was less than $5 \%$ in all cases, probably due to $\mathrm{H}_{2} \mathrm{O}_{2}$ auto-decomposition at elevated $\mathrm{pH}$ values.

The efficacy of promoted photolysis proved dependent on the rate of $\mathrm{pH}$ decrease (from initial to value below $\mathrm{pK}_{\mathrm{a}}$ ) at the beginning of the process. After reaching acidic $\mathrm{pH}$ of the surrounding solution the DCF degradation was stable and controlled by the solubility independently of treatment method applied. The highest efficacy improvement was attained in $\mathrm{UV} / \mathrm{H}_{2} \mathrm{O}_{2} / \mathrm{a}-\mathrm{FeOOH}$ system at $\mathrm{pH} 11$, where $\mathrm{pH}$ decreased only to 10 , and the process was not determined by the solubility equilibrium of DCF. The $T_{90 \%}$ for UV photolysis and heterogeneous photo-Fenton process $\left(3.8 \mathrm{mM} \mathrm{H}_{2} \mathrm{O}_{2}\right.$ ) was 48 and $23.5 \mathrm{~min}$, respectively (Figure 4).

Similar to UV and UV/ $\mathrm{H}_{2} \mathrm{O}_{2}$ systems, no substantial mineralization of DCF was observed in any studied Fentonbased process with initial $\mathrm{pH} 7$ and 9. COD removal was $\mathrm{ca}$ $15 \%$ after $2 \mathrm{~h}$ of oxidation. In the case of $\mathrm{pH} 11$ and elevated $\mathrm{H}_{2} \mathrm{O}_{2}$ concentration (1.9 mM), COD was essentially reduced (up to $60 \%$ ) indicating overall efficacy of the process under strongly alkaline conditions.

\section{Identification of intermediates}

In the present study, no derivatization procedures were undertaken prior to injection of the samples into GC-MS (EI) system, and highly polar or non-volatile by-products could escape the scope of the technique. Identification of by-products was done by comparison of full-scan mass spectra of the peaks with mass spectral library (NIST/EPA/NIH (NIST 08)) or by identification of the fragmentation patterns.

The results of the present study indicated similar GC-MS chromatogram patterns for UV photolysis, $\mathrm{UV} / \mathrm{H}_{2} \mathrm{O}_{2}$ and $\mathrm{UV} / \mathrm{H}_{2} \mathrm{O}_{2} / \mathrm{a}-\mathrm{FeOOH}$ systems. Two photo-transformation products were detected; other by-products were in trace concentrations (below the method detection limits) even during the first few minutes of DCF degradation. The main detected photo-transformation product with formula $\mathrm{C}_{14} \mathrm{H}_{9} \mathrm{Cl}_{2} \mathrm{NO}$ (MW 277) was identified as 1-(2,6-dichlorophenyl) indolin-2-one. This compound was also reported [4] as one of the major photo-decomposition products of DCF in pure water. However, the application of GC-MS for sample analysis could be the reason for such observation, since 1-(2,6-dichlorophenyl)indolin-2-one can be formed due to a high temperature used in this method. The other observed photo-transformation product with formula $\mathrm{C}_{14} \mathrm{H}_{10} \mathrm{CINO}$ (MW 243) was apparently described as $\mathrm{C}-2$ (8-chloro-9H-carbazole1-acetic aldehyde) [21]. The analysis of mass spectrum of the latter by-product indicated mass differences of $\Delta=28$ and $\Delta=35$ pointing to the existence of one chlorine atom and an aldehyde function. In order to prove this assumption further detailed analysis is required.

\section{Conclusions}

DCF was quite resistant to all tested AOPs. The application of the Fenton-based treatment and $U V / \mathrm{H}_{2} \mathrm{O}_{2}$ did not show vital advantages compared to UV photolysis when the initial $\mathrm{pH}$ was 7 or 9 . Direct photolysis proved main process contributing to DCF degradation in all studied systems combined with UV irradiation. The fast $\mathrm{pH}$ decrease of the surrounding solution to 3.5 observed during all studied processes started at $\mathrm{pH} 5,7$ and 9 led to system controlled by DCF precipitation-degradation-re-dissolution. The efficacy of $\mathrm{UV} / \mathrm{H}_{2} \mathrm{O}_{2}$, homogeneous and heterogeneous photo-Fenton systems proved dependent on time of $\mathrm{pH}$ decrease at the beginning of the process. After reaching $\mathrm{pH}$ values below DCF $\mathrm{pK}_{\mathrm{a}}$ the degradation was controlled by the solubility independently of treatment method applied. The present study was the first to evaluate the efficacy of photo-Fenton catalysed by goethite for DCF degradation in aqueous solution. The latter proved the most efficient one among the Fenton-based processes. The identification of DCF degradation by-products by GC-MS (EI) technique was done indicating 1-(2,6-dichlorophenyl)indolin-2-one and 8-chloro-9H-carbazole-1-acetic aldehyde as two detectable photo-transformation products.

\section{Competing interests}

The authors declare that they have no competing interests.

\section{Authors' contributions}

IE contributed to research design, fulfilled the experiments and analyses, contributed to data interpretation and drafted the manuscript. ND contributed in conception, research design, data interpretation and manuscript draft. MT contributed in conception, research design and manuscript draft. All authors approved the manuscript.

\section{Acknowledgements}

The financial support of the Estonian Science Foundation (grant 8186) and Estonian Research Council (project IUT01-07) is gratefully acknowledged.

\section{Publication history}

Editor: Naresh Singhal, University of Auckland, New Zealand. Received: 20-Sep-2012 Revised: 19-Oct-2012

Accepted: 28-Oct-2012 Published: 17-Nov-2012

\section{References}

1. Vieno NM, Harkki H, Tuhkanen T, Kronberg L: Occurrence of pharmaceuticals in river water and their elimination in a pilot-scale drinking water treatment plant. Environ Sci Technol 2007, 41:5077-5084. | Article | PubMed

2. Klamerth N, Rizzo L, Malato S, Maldonado MI, Aguera A, FernandezAlba AR: Degradation of fifteen emerging contaminants at microg L(-1) initial concentrations by mild solar photo-Fenton in MWTP effluents. Water Res 2010, 44:545-554. | Article | Pub Med

3. Zhang Y, Geissen SU, Gal C: Carbamazepine and diclofenac: removal in wastewater treatment plants and occurrence in water bodies. Chemosphere 2008, 73:1151-1161. | Article | PubMed

4. Bartels P, von Tumpling W, Jr.: Solar radiation influence on the decomposition process of diclofenac in surface waters. Sci Total Environ 2007, 374:143-155. | Article | PubMed 
5. Pérez-Estrada LA, Maldonado MI, Gernjak W, Agüera A, FernándezAlba AR, Ballesteros MM, Malato S: Decomposition of diclofenac by solar driven photocatalysis at pilot plant scale. Catalysis Today 2005, 101:219-226. I Article

6. Klavarioti M, Mantzavinos D, Kassinos D: Removal of residual pharmaceuticals from aqueous systems by advanced oxidation processes. Environ Int 2009, 35:402-417. | Article | PubMed

7. Kim I, Yamashita N, Tanaka H: Performance of UV and UV/H2O2 processes for the removal of pharmaceuticals detected in secondary effluent of a sewage treatment plant in Japan. J Hazard Mater 2009, 166:1134-1140. | Article | PubMed

8. Baeza C, Knappe DR: Transformation kinetics of biochemically active compounds in low-pressure UV photolysis and UV/H(2)O(2) advanced oxidation processes. Water Res 2011, 45:4531-4543. | Article | PubMed

9. Hofmann J, Freier U, Wecks M, Hohmann S: Degradation of diclofenac in water by heterogeneous catalytic oxidation with $\mathrm{H} 2 \mathrm{O2}$. Applied Catalysis B: Environmental 2007, 70:447-451. | Article

10. Dulova N, Trapido M, Dulov A: Catalytic degradation of picric acid by heterogeneous Fenton-based processes. Environ Technol 2011, 32:439-446. | Article | PubMed

11. Garrido-Ramírez EG, Theng BKG, Mora ML: Clays and oxide minerals as catalysts and nanocatalysts in Fenton-like reactions - A review. Applied Clay Science 2010, 47:182-192. | Article

12. Lu MC: Oxidation of chlorophenols with hydrogen peroxide in the presence of goethite. Chemosphere 2000, 40:125-130. | Article | PubMed

13. Gordon AJ, Ford RA: The Chemist's Companion. A Handbook of Practical Data, Techniques and References. Wiley, NewYork 1972, pp.373-376. | Link

14. APHA (American Public Health Association). Standard Methods for the Examination of Water and Wastewater (2005). 21st edn, American Water Works Association, Water Environment Federation, Washington DC.

15. Eisenberg G: Colorimetric Determination of Hydrogen Peroxide. Industrial \& Engineering Chemistry Analytical Edition 1943, 15:327328. | Article

16. Kang YW, Cho M-J, Hwang K-Y: Correction of hydrogen peroxide interference on standard chemical oxygen demand test. Water Research 1999, 33:1247-1251. | Article

17. Palomo ME, Ballesteros MP, Frutos $\mathrm{P}$ : Analysis of diclofenac sodium and derivatives. J Pharm Biomed Anal 1999, 21:83-94. | Article | PubMed

18. Rivas J, Gimeno O, Borralho T, Beltrán F: Influence of oxygen and free radicals promoters on the UV-254-nm photolysis of diclofenac. Chemical Engineering Journal 2010, 163:35-40. | Article

19. Canonica S, Meunier L, von Gunten U: Phototransformation of selected pharmaceuticals during UV treatment of drinking water. Water Res 2008, 42:121-128. | Article | PubMed

20. Vogna D, Marotta R, Napolitano A, Andreozzi R, d'Ischia M: Advanced oxidation of the pharmaceutical drug diclofenac with UV/H2O2 and ozone. Water Res 2004, 38:414-422. | Article | PubMed

21. Aguera A, Perez Estrada LA, Ferrer I, Thurman EM, Malato $S$, Fernandez-Alba AR: Application of time-of-flight mass spectrometry to the analysis of phototransformation products of diclofenac in water under natural sunlight. J Mass Spectrom 2005, 40:908-915. | Article | PubMed

\section{Citation:}

Epold I, Dulova N and Trapido M: Degradation of diclofenac in aqueous solution by homogeneous and heterogeneous photolysis. journal of Environmental Engineering and Ecological Science 2012, 1:3. http://dx.doi.org/10.7243/2050-1323-1-3 